\title{
O Concílio Vaticano II e o diálogo inter-religioso: os avanços na busca por um novo paradigma teológico
}

\author{
Second Vatican Council and interreligious \\ dialogue: the advances in the search for a \\ new theological paradigm
}

Francilaide de Queiroz Ronsi

\section{Resumo}

Celebrando 50 anos do Concílio Vaticano II fazemos memória dos avanços iniciados em sua reflexão, em especial, no que diz respeito ao diálogo inter-religioso quando nos propõe uma mudança de paradigma, rompendo com o eclesiocentrismo. Passados 50 anos de sua realização, nos defrontamos com o pluralismo religioso que nos convida a buscar formas que possibilitem o convívio harmonioso em nossa sociedade. Veremos que essa realidade para o cristianismo, com sua atual configuração, o provoca mais do que em outra época a abrir-se para o reconhecimento das outras religiões. A teologia se vê, então, confrontada de uma maneira inédita em sua história com a tarefa da interpretação das religiões e do próprio fato do pluralismo religioso à luz da revelação cristã e com uma reinterpretação da fé cristã dentro do horizonte hermenêutico fornecido pela realidade inter-religiosa atual. Procuraremos situar os principais desafios na busca por um paradigma que possa melhor corresponder à realidade de pluralismo religioso. A provocação principal que se impõe é encontrar um paradigma para a reflexão teológica que possibilite à fé cristã o reconhecimento positivo, justo e respeitoso da pluralidade e diversidade religiosa, porém, sem abandonar a identidade cristã.

Palavras-chave: Diálogo inter-religioso. Pluralismo. Paradigma. Mística. 


\begin{abstract}
Celebrating Second Vatican Council's 50 years we remember its advances, in particular, regarding the interreligious dialogue which invites us to a change of paradigm, breaking with the ecclesiocentrism. After 50 years, we face a religious pluralism that invites us to look for ways to enable the harmonious coexistence in our society. We will see that this reality to christianity, with its current configuration, incites us more than ever to open up for the recognition of other religions. Theology can be seen, then, facing an unprecedented way in its history with the task of interpretation of religions and the fact of religious pluralism in the light of christian revelation and a reinterpretation of the christian faith within the hermeneutical horizon provided by the current international reality of religion. We will seek to situate the main challenges in the search for a paradigm that can better match the reality of religious pluralism. The main provocation that is needed is to find a paradigm for theological reflection that allows the christian faith to a positive recognition, fair and respectful of pluralism and religious diversity, but without abandoning the christian identity.
\end{abstract}

Keywords: Interreligious dialogue. Pluralism. Paradigm. Mystical.

\title{
Introdução
}

O Concílio Vaticano II, com ousadia, deu um grande salto com relação às outras religiões ${ }^{1}$. Seu ensino sobre as religiões se caracterizou por uma atitude positiva diante das outras religiões, possibilitando renovação teológica pósconciliar ${ }^{2}$. O Concílio afirmou respeitar e valorizar tudo de bom e santo que é suscitado pelo Espírito em outras tradições, declarando o caráter "verdadeiro e santo" das outras religiões, reconhecendo elementos positivos de vida e santidade presentes nas religiões não cristãs ${ }^{3}$. Reconheceu que a salvação dos seres humanos vai muito além dos limites da Igreja. Por intermédio do

\footnotetext{
${ }^{1}$ Cf. VIGIL, J. Maria. Teologia do pluralismo religioso. Para uma releitura pluralista do cristianismo. São Paulo: Paulus, 2006, p. 77.

${ }^{2}$ Cf. LG, 16 e 17; AG, 3, 9 e 11; Também NA; DV e DH apresentam importantes contribuições à questão.

${ }^{3}$ Cf. NA, 2; UR, 3; LG,13.
} 
Espírito Santo, Deus “opera de modo invisível" e oferece a todos a salvação ${ }^{4}$, admitindo e proclamando que Deus salva a humanidade "por caminhos só por ele conhecidos"s.

Esse Concílio marcou uma abertura sem precedentes nos posicionamentos oficiais da Igreja, determinando uma nova fase em sua relação com os não cristãos ${ }^{6}$. A partir dessa posição, estabelece-se uma oportunidade decisiva para o desenvolvimento da teologia das religiões nos anos pós-conciliares, pois nele se falou sobre as religiões não cristãs de um modo mais positivo do que nenhum outro documento oficial da Igreja Católica havia feito antes ${ }^{7}$.

No entanto, o Concílio não teve tempo de ir mais além. Ele não questionou se era possível afirmar que as próprias religiões não cristãs são caminhos de salvação para seus membros por si mesmas, e não por uma participação sua no mistério de Cristo. Sua preocupação manteve-se em promover a compreensão, o diálogo, a acolhida e a cooperação entre o cristianismo e as religiões, suscitando, ao mesmo tempo, uma mudança de atitude por parte da Igreja e dos cristãos em relação às mesmas ${ }^{8}$.

O Concílio foi uma ocasião em que uma Igreja cristã tomou a sério e se pronunciou sobre as religiões não cristãs de uma forma sem precedentes nem paralelos em toda a história. Suas afirmações significaram uma porta aberta aos teólogos, que se encontravam diante de um tema inédito, numa etapa nova de relação entre as mais diversas tradições religiosas ${ }^{9}$. Embora tenha reconhecido o juízo teológico claro sobre o sentido salvífico das mesmas ${ }^{10} \mathrm{e}$ sobre o significado do pluralismo religioso, deixou como tarefa para a reflexão teológica posterior examinar o alcance e tirar as consequências das afirmações desenvolvidas no mesmo.

\footnotetext{
${ }^{4}$ Cf. GS, 22.

${ }^{5} \mathrm{GS}, 22$.

${ }^{6}$ Sobre a teologia das religiões no Magistério da Igreja após o Concílio. Cf. DUPUIS, Jacques. Rumo a uma teologia cristã do pluralismo religioso. São Paulo: Paulinas, 1999, p. 250ss. TEIXEIRA, Faustino. Teologia das religiões: uma visão panorâmica. São Paulo: Paulinas, 1995, pp. 138-179.

${ }^{7}$ Cf. VIGIL, J. Maria. Teologia do pluralismo religioso, p. 81.

${ }^{8}$ Cf. DUPUIS, Jacques. Rumo a uma teologia cristã, p. 224.

${ }^{9}$ Cf. SULlIVAN, Francis A. ¿Hay salvación fuera de la Iglesia?. Desclée: Bilbao, 1999. Apud. VIGIL, J. Maria. Teologia do pluralismo religioso, p. 61.

10 Cf. MIRANDA, M. de França. O cristianismo em face das religiões. Religiões em diálogo. São Paulo: Loyola, 1998, p. 13.
} 
Propusemo-nos identificar os principais 'paradigmas' que dominaram a tentativa de construir uma teologia das religiões e do pluralismo religioso. Colocaremos, em primeiro plano, uma classificação tripartite universalmente aceita por sua clareza e simplicidade, ainda que alguns teólogos considerem esta classificação insuficiente ${ }^{11}$, tendo em vista que foi de um modo ou de outro, universalmente admitida. Dos modelos ou posições no âmbito da teologia das religiões, esta classificação distingue três perspectivas fundamentais: eclesiocêntrica, cristocêntrica e teocêntrica. A estas três perspectivas correspondem três posições básicas, respectivamente: exclusivismo, inclusivismo e pluralismo ${ }^{12}$. Essas distinções correspondem a uma dupla mudança de paradigma ${ }^{13}$.

\section{Superando paradigmas}

Procuraremos aqui, seguindo Dupuis, explicar as pressões que fizeram com que a teologia das religiões passasse por uma dupla mudança de paradigma, do eclesiocentrismo ao cristocentrismo, e do cristocentrismo ao teocentrismo, o que torna evidente que a questão cristológica, que originalmente se encontrava no centro de toda discussão da teologia das religiões, tende, na opinião de muitos - com ou sem razão -, a uma progressiva marginalização. Será preciso "ir à procura de um modelo praticável para uma teologia sintética das religiões que seja ao mesmo tempo cristã e aberta"14.

Nessa classificação, o exclusivismo, como paradigma de teologia das religiões, é equivalente ao eclesiocentrismo: a Igreja se converte em centro da ação missionária ou mediação obrigatória da salvação. Essa foi a posição teológica hegemônica no cristianismo. Em uma "história tão dilatada no tempo e no espaço não é difícil encontrar pensadores e correntes eclesiais nos quais se vislumbram traços de uma concepção mais ampla da salvação" ${ }^{15}$. No mundo católico, esse paradigma foi sustentado por vinte séculos e teve como expressão simbólica máxima a famosa sentença Extra ecclesium nulla salus

\footnotetext{
${ }^{11}$ Cf. Por exemplo: VIGIL, J. Maria. Teologia do pluralismo religioso, p. 62.

${ }^{12}$ Cf. DUPUIS, Jacques. Rumo a uma teologia cristã, pp. 257-264; MIRANDA, M. de França. O cristianismo em face das religiões, pp. 16-19; TEIXEIRA, Faustino. Teologia das religiões, pp. 37-77.

${ }^{13}$ Cf. DUPUIS, Jacques. Rumo a uma teologia cristã, pp. 106-107.

${ }^{14}$ Ibid., p. 107.

${ }^{15}$ VIGIL, J. Maria. Teologia do pluralismo religioso, p. 73.
} 
(fora da Igreja não há salvação) ${ }^{16}$. Se, na sua origem, este axioma, ao afirmar o papel da Igreja, não reivindicava sua exclusividade, ao longo da história, recebeu uma interpretação rígida, que resultou na negação da possibilidade de salvação fora da Igreja e num olhar pessimista com relação às outras religiões ${ }^{17}$.

No campo protestante, o exclusivismo adquire uma forma não eclesiocêntrica, porém centrada no tríplice princípio sola fide, sola gratia, sola scriptura (só a fé, só a graça, só a escritura). Para K. Barth, as religiões - todas, menos a religião bíblico-cristã - são, definitivamente, um esforço humano, uma tentativa de captar a benevolência de Deus. E a salvação vem unicamente pela entrega do ser humano - mediante a fé - à graça que o próprio Deus lhe oferece em Jesus Cristo. Para ele, somente a aceitação da graça de Deus vinda por Jesus Cristo pode salvar o ser humano ${ }^{18}$.

Esta posição foi oficialmente condenada pelo magistério da Igreja mediante a condenação do Santo Ofício da interpretação estreita da expressão 'fora da Igreja, não há salvação' ${ }^{19}$. Foi efetivamente descartada pelas afirmações do Vaticano II sobre a vontade salvífica universal de Deus e sobre os valores positivos presentes nas outras religiões, juntamente com a possibilidade de salvação fora da Igreja ${ }^{20}$. No entanto, permanece a questão da função salvífica de Jesus Cristo e a universalidade da vontade salvífica de Deus.

O Concílio Vaticano II marcou a mudança de paradigma quando rompeu com o exclusivismo do eclesiocentrismo. Nesse contexto, surge o inclusivismo assumindo o cristocentrismo, posição segundo a qual, ainda que a verdade e a salvação estejam plenamente presentes numa determinada religião, também se faz presente - de modo mais ou menos deficiente ou imperfeito - nas outras religiões, porém como participação na verdade e na salvação presentes na única religião verdadeira, reconhecendo, então, que a

\footnotetext{
${ }^{16}$ Cf. Ibid., p. 74.

${ }^{17}$ Sobre a história deste axioma Cf. DUPUIS, Jacques. Rumo a uma teologia cristã, pp. 123-155.

${ }^{18}$ Cf. BARTH, Karl. La revelación como abolición de la religión. Madri: Morova, 1973. Apud. VIGIL, J. Maria. Teologia do pluralismo religioso, p. 75. Karl Barth (1886-1968) foi um teólogo cristão-protestante, pastor da Igreja Reformada, e um dos líderes da teologia dialética e da neo-ortodoxia protestante. Em um momento de sua carreira teológica, migra da teologia puramente dialética e passa a utilizar a analogia da fé. Para ele, a analogia seria a única forma viável de se falar de Deus.

${ }^{19}$ Cf. MIRANDA, M. de França. O cristianismo em face das religiões, p. 157; TEIXEIRA, Faustino. Teologia das religiões, pp. 39-40.

${ }^{20}$ Cf. DUPUIS, Jacques. Rumo a uma teologia cristã, p. 159.
} 
salvação pode se dar nas demais religiões, sem, no entanto, reconhecer nelas autonomia salvífica ${ }^{21}$.

O cristocentrismo coloca no centro da reflexão o mistério de Jesus Cristo, o que implica um 'des-centramento' da Igreja e um 're-centramento' em Jesus Cristo. "É este último, e não a Igreja, que está no centro do mistério cristão; a Igreja é, ao contrário, um mistério derivado, relativo, que encontra n'Ele sua razão de ser"22.

O cristocentrismo adquiriu os seguintes contornos: somente a religião cristã tem a verdade e a salvação; ainda que em outras religiões também haja elementos de Verdade. Participando, pois, da salvação também os não cristãos, porém não por uma suposta validez de suas próprias religiões, e sim pelo poder de Cristo, que alcança a salvação para eles "de uma maneira somente conhecida de Deus" ${ }^{23}$. Esta posição abriu um novo caminho no mundo teológico, em especial no campo católico, após o Concílio Vaticano II.

Entretanto, foram duas posições teológicas que prepararam o caminho até este Concílio e que ainda se desdobram no cristocentrismo: a teoria do cumprimento e a teoria da presença de Cristo nas religiões ${ }^{24}$. A teoria do cumprimento sustentava que, para todas as religiões, o cristianismo vem a ser seu cumprimento, ou seja, sua consumação e, nesse sentido, seu acabamento, sua plenitude e, também sua superação. Esta teoria considerava que as religiões não cristãs não têm capacidade salvífica por si mesmas, pois seriam religiões 'naturais', obra do ser humano que busca a Deus. E segundo Vigil, nesta corrente estão, com diferentes matizes, Jean Daniélou, Henri de Lubac e Hans Urs von Balthasar, teólogos do período pré-conciliar e conciliar ${ }^{25}$.

A teoria da presença de Cristo nas religiões, que significa para Karl Rahner dizer que todos os que "aceitam livremente a oferta da auto-comunicação de Deus mediante a fé, a esperança e o amor, entram na categoria de 'cristãos anônimos"" ${ }^{26}$, ou seja, que toda a humanidade estava inserida na salvação de Cristo.

\footnotetext{
${ }^{21}$ Cf. MIRANDA, M. de França. O cristianismo em face das religiões, p. 17.

${ }^{22}$ DUPUIS, Jacques. Rumo a uma teologia cristã, p. 259.

${ }^{23} \mathrm{GS}, 22$.

${ }^{24}$ Cf. VIGIL, J. Maria. Teologia do pluralismo religioso, p. 77.

${ }^{25}$ Cf. VIGIL, J. Maria. Teologia do pluralismo religioso, p. 78.

${ }^{26}$ Ibid., p. 79.
} 
Foi o pensamento de K. Rahner ${ }^{27}$ que mais influiu no Concílio Vaticano II. Rahner afirmava que as religiões têm valores salvíficos positivos, já que, por elas, a graça de Cristo efetivamente alcança seus membros. Foi a primeira vez que, no cristianismo, se dizia de um momento tão explícito e fundamentado que a graça e o mistério de Cristo superavam inteiramente a Igreja. Era uma visão cheia de otimismo diante do pessimismo da visão exclusivista ${ }^{28}$. Os principais representantes desta teoria são, além de K. Rahner, Raimon Panikkar, Hans Küng e Gustavo Thils ${ }^{29}$.

No entanto, mesmo que provocando um grande salto qualitativo, esta posição, segundo alguns teólogos, permanece problemática. Isso se deve à noção de que, ao sustentar o caráter absoluto de Jesus Cristo, acaba afirmando a superioridade do Cristianismo com relação às outras tradições religiosas. Esta superioridade representa um obstáculo para o diálogo inter-religioso. Por isso, na busca de solução desta problemática, alguns autores começaram a defender uma nova e mais radical mudança de paradigma, propondo a superação do cristocentrismo com o teocentrismo ${ }^{30}$.

Surge o teocentrismo, uma posição pluralista $^{31}$, que, em relação ao exclusivismo no qual se afirma que só uma religião é verdadeira e todas são falsas, seria dito nesta nova posição necessariamente o contrário, ou seja, que todas as religiões são igualmente verdadeiras e equivalentes e estão todas equidistantes da verdade ${ }^{32}$. Ao seu redor estão todas as religiões que se relacionam com Deus diretamente, sem a mediação cristã.

Logo, esta mudança do cristocentrismo para o teocentrismo implica na rejeição da centralidade de Jesus Cristo. Com efeito, "para salvar um pluralismo salvífico era necessário romper o vínculo salvífico de Jesus

${ }^{27}$ Karl Rahner (1904-1984), um dos maiores teólogos do séc. XX. Rahner está entre os pensadores cristãos que procuraram estabelecer uma ponte entre o tomismo, (tradicionalmente cultivado pela intelectualidade católica) e a filosofia moderna (Kant, Hegel, Heidegger), filiando-se, assim, ao que se convencionou chamar de Tomismo Transcendental.

${ }^{28}$ Cf. VIGIL, J. Maria. Teologia do pluralismo religioso, pp. 78-79.

${ }^{29}$ Cf. DUPUIS, Jacques. Rumo a uma teologia cristã, pp. 219-221.

${ }^{30}$ Cf. Ibid., pp. 260-264; TEIXEIRA. Faustino. Teologia das religiões, pp. 58-74.

${ }^{31}$ Aqui pluralismo não significa pluralidade das religiões, e sim um paradigma de pensamento da teologia das religiões. Sobre a distinção entre pluralismo e pluralidade. Cf. JAYANTH, Mathew. "De la pluralidad al pluralismo". Selecciones de Teologia 163 (2002), pp. 163-176. Apud. VIGIL, J. Maria. Teologia do pluralismo religioso, p. 63.

${ }^{32}$ Cf. VIGIL, J. Maria. Teologia do pluralismo religioso, p. 88. 
Cristo com Deus como único e exclusivo, era preciso separar Cristo-logia de teo-logia"33.

Pluralismo é a posição teológica segundo a qual todas as religiões participam da salvação de Deus. Nessa posição, sustenta-se que uma sincera busca cristã do diálogo com as outras religiões requer a renúncia a toda pretensão de unicidade salvífica para a pessoa e a obra de Jesus Cristo. Para esta posição teológica, somente Deus está no centro. Em todas as religiões, Deus sai ao encontro do ser humano, sem que haja apenas uma única religião verdadeira. Isto implica uma mudança radical no cristianismo ${ }^{34}$.

No entanto, todos esses paradigmas mostraram-se insuficientes para resolver o duplo desafio da relação do cristianismo com as outras religiões. Irão surgir outros modelos procurando salvaguardar a identidade cristã, os quais articulem os dois axiomas fundamentais da fé cristã - a vontade salvífica universal por parte de Deus e a necessária mediação de Cristo - sem, contudo, se fecharem à novidade proposta por outras tradições religiosas reconhecendoas em sua alteridade.

Observamos que o exclusivismo, ao dar uma ênfase unilateral ao segundo axioma, entra em sérias contradições teológicas e não tem sustentação bíblica $^{35}$. É descartada entre os teólogos católicos a posição exclusivistaeclesiocêntrica. Sobre o inclusivismo, Knitter questiona um dos seus pilares, que é o caráter único da pessoa de Jesus Cristo como critério para a salvação universal. Segundo ele, "Jesus realmente é a Palavra da Verdade de Deus, essencial para todos os povos, e não que Ele seja a única palavra de Verdade, essencial para todos os povos" $"$.

Os inclusivistas questionam as afirmações pluralistas, mesmo que acreditem nas suas importantes contribuições. Para esses, as afirmações pluralistas orientam-se pelo axioma da vontade salvífica universal de Deus e deixam de lado a mediação de Jesus Cristo.

\footnotetext{
${ }^{33}$ MIRANDA, M. de França. “O encontro das religiões”. Perspectiva Teológica 68 (1994), p. 20.

${ }^{34}$ Cf. VIGIL, J. Maria. Teologia do pluralismo religioso, pp. 63-64.

${ }^{35}$ Cf. DUPUIS, Jacques. Rumo a uma teologia cristã, p. 269.

${ }^{36}$ KNITTER, Paul. Diálogo inter-religioso e ação missionária: preparai os caminhos. São Paulo: CNBB/COMINA, 1994, p. 09. Paul F. Knitter é professor de Teologia, Religião e Cultura no Mundo União Theological Seminary na Cidade de Nova Iorque. Desde a publicação do seu livro, nenhum outro nome? (1985), Knitter foi amplamente conhecido por seu pluralismo religioso jAlong with his friend and colleague, the Protestant philosopher of religion John Hick , Knitter has come under harsh criticism from Cardinal Ratzinger (presently the Pope of the Roman Catholic Church ).unto com seu amigo e colega, o filósofo da religião protestante John Hick.
} 
Entretanto, é certo que, embora a pretensão de unicidade e universalidade da salvação cristã apresente dificuldades para o diálogo inter-religioso, não pode, no entanto, uma teologia cristã das religiões desprezar as afirmações do Novo Testamento e de toda a tradição de experiências cristã sobre a revelação divina decisiva e definitiva em Jesus Cristo. Essa posição colocaria em jogo os aspectos fundamentais da fé cristã e separaria teologia e cristologia, o que é impossível numa teologia cristã ${ }^{37}$.

O pluralismo teocêntrico incorre numa interpretação nominalista das religiões, interpretando-as como diversas expressões de uma mesma realidade e numa interpretação essencialista das mesmas ao abordá-la sob o pressuposto de um denominador comum ${ }^{38}$.

No entanto, diante dessas questões teológicas, irão surgir outros modelos ligados ao paradigma teocêntrico. Emergem o 'reinocentrismo' e 'soteriocentrismo', perspectivas nas quais nem a Igreja, nem Jesus Cristo, nem Deus são centros. O centro é o objeto da pregação de Jesus Cristo: o Reino de Deus e a salvação. Em torno desse é que se devem centrar a reflexão e a prática das religiões ${ }^{39}$.

Ao colocar o Reino de Deus no centro, o reinocentrismo interpreta as religiões numa perspectiva escatológica, segundo a qual Deus e o Reino são a meta da história comum a todas as religiões. Possibilita, assim, uma interpretação fecunda, na medida em que reconhece que os membros de outras religiões, juntamente com os cristãos, "já são membros do Reino de Deus na história [...] dirigindo-se, todos juntos, para a plenitude escatológica de Deus"40. No entanto, o reinocentrismo continua se apoiando num conceito de Deus típico do monoteísmo, mas especificamente no conceito cristão, e coloca-se mais na linha do cristocentrismo.

Nesse contexto, outra tentativa foi superar o inclusivismo com o 'logocentrismo' e o 'pneumatocentrismo', que se baseiam na presença e na ação universal do Verbo e do Espírito de Deus, como dois modelos que poderiam substituir o cristocentrismo ${ }^{41}$. Entretanto, estão intrinsecamente vinculados

\footnotetext{
${ }^{37}$ Cf. DUPUIS, Jacques. Rumo a uma teologia cristã, p. 270; AMALADOSS, M. "O pluralismo das religiões e significado de Cristo". In: TEIXEIRA, Faustino. Diálogo de pássaros. Nos caminhos do diálogo inter-religioso. São Paulo: Paulinas, 1993, p. 91s.

${ }^{38}$ Cf. AMALADOSS, M. O pluralismo das religiões e significado de Cristo, p. 92.

${ }^{39}$ Cf. DUPUIS, J. O cristianismo e as religiões, pp.111-113; Id., Rumo a uma teologia cristã, pp. 270-272.

${ }^{40}$ Ibid., pp. 114-116; Id., Rumo a uma teologia Cristã, p. 272.

${ }^{41}$ Cf. DUPUIS, Jacques. Rumo a uma teologia cristã, pp. 173-277.
} 
com o cristocentrismo numa única economia e não podem representar uma importante contribuição para a teologia das religiões ${ }^{42}$.

Um novo modelo surge para ser o que podemos considerar o 'ponto de equilíbrio' entre o inclusivismo e o pluralismo: é o "inclusivismo aberto"43. Mesmo que desenvolvido para encontrar o "equilíbrio"44, este novo modelo irá tender ao cristocentrismo ou ao teocentrismo. Há uma propensão em afirmar, nesse novo paradigma, a autonomia salvífica das religiões, ao mesmo tempo em que se assegura o caráter único e particular que Jesus Cristo exerce na História da Humanidade e, por consequência, na história da salvação, pois, "fora do mundo, não há salvação"45. O mundo aí é entendido como plenitude não fechada no cristianismo, mas de forma "relativa e aberta"46.

No entanto, o debate não para. As discussões e a procura por um paradigma que possa corresponder às necessidades, sem cair no absolutismo e nem no relativismo, são cada vez impulsionadas por uma inegável realidade, $o$ pluralismo. Este deve ser levado a sério como lugar no desígnio de Deus para a salvação da humanidade.

\section{A busca por um novo paradigma teológico}

O debate persiste. Hoje, diante desta inegável realidade plural, em que "praticamente todas as religiões entraram em contato" 47 e todas estão presentes umas às outras, inevitavelmente, surgem da teologia asiática novas abordagens sobre a problemática inter-religiosa, provenientes da prática do diálogo, das experiências de encontro e da convivência com outras tradições religiosas ${ }^{48}$.

\footnotetext{
${ }^{42}$ Dupuis propõe a não-separação, mas a interligação entre esses paradigmas. Para ele, Jesus Cristo, Reino de Deus e Espírito Santo são realidades inseparáveis. Cf. DUPUIS, J. O debate cristológico no contexto do pluralismo religioso, p. 75ss; KNITTER, Paul. Diálogo inter-religioso e ação missionária; Id., "A teologia católica das religiões numa encruzilhada". Concilium v. 203, n. 1, p.112.

${ }^{43}$ Nomenclatura presente em: TEIXEIRA, Faustino. Teologia das religiões, p.78ss.

44 AMALADOSS, M. "O pluralismo das religiões e significado de Cristo". In: TEIXEIRA, Faustino. Diálogo de pássaros, p. 107.

${ }^{45}$ SCHILLEBEECK, E. História humana. Revelação de Deus. São Paulo: Paulus, 1994, p. 21.

${ }^{46}$ QUEIRUGA, A. Torres. O diálogo das religiões. São Paulo: Paulus, 1997, p. 27.

${ }^{47}$ Ibid., p. 61.

${ }^{48}$ Cf. DUPUIS, Jacques. Rumo a uma teologia cristã, p. 278; Cf. AMALADOSS, M. Pela estrada da vida. Prática do diálogo inter-religioso. São Paulo: Paulinas, 1996. Nessa obra, o autor reúne vários artigos que têm como base a experiência de encontro e convivência entre pessoas de diferentes religiões.
} 
As novas abordagens caracterizam-se pelo esforço em descobrir e reconhecer a especificidade e singularidade das outras religiões e uma maior atenção ao fato do pluralismo religioso a partir da própria perspectiva de fé, pois, "o pluralismo religioso - sugere-se - mergulha suas raízes na profundidade do próprio Mistério divino e nas variadas formas com que as culturas humanas lhe responderam" ${ }^{\prime 4}$. Assim, Deus criador torna-se presente e ativo na pluralidade das religiões.

Nesse sentido, provocaria uma nova busca para a reflexão, procurando reconhecer a especificidade e singularidade de cada tradição religiosa.

Segundo a Declaração publicada pela XIII Reunião Anual da Associação Teológica Indiana, são criticadas as categorias em uso na teologia das religiões, por abordarem a religião dos outros de modo abstrato, acadêmico e especulativo e do ponto de vista de uma única cultura religiosa ${ }^{50}$. Elas [as categorias] traem "a aproximação teórica à fé de outras pessoas", que nascem "de uma sociedade caracterizada por uma só cultura religiosa e por um ponto de vista meramente acadêmico e especulativo" ${ }^{1}$.

Todavia, neste momento, na teologia cristã das religiões, que tem procurado superar suas muitas contradições, parece estar emergindo um consenso para evitar qualquer tipo de absolutismo ou relativismo. Isso se deve ao fato de se reconhecer que a grande questão em debate, hoje, passou a ser a pluralidade das religiões, o pluralismo religioso. Entende-se, então, que "uma teologia das religiões, não pode deixar de ser, definitivamente, uma teologia do pluralismo religioso" ${ }^{52}$. O que acaba sendo um novo nome adotado em nossos dias para a teologia das religiões, novo ramo da teologia.

Tal mudança terminológica demarca uma mudança na perspectiva teológica, que procura superar as categorias de inclusivismo e pluralismo por um 'novo paradigma teológico" ${ }^{53}$. Desloca-se, assim, a reflexão teológica, do problema da salvação mediante as outras religiões para o próprio fenômeno do pluralismo religioso.

Coloca-se, agora, a questão da origem do próprio pluralismo, "o seu

\footnotetext{
${ }^{49}$ DUPUIS, Jacques. O cristianismo e as religiões, p. 117.

${ }^{50}$ Cf. Ibid., p.118.

${ }^{51}$ Declaração da XII reunião anual da associação de teólogos da Índia, em 28 a 31 de dezembro de 1989. n. 4. Apud. DUPUIS, Jacques. Rumo a uma teologia cristã, p. 118.

${ }^{52}$ Ibid., p. 271.

${ }^{53} \mathrm{Cf}$. Id., "Le pluralisme religieux dans le plan divin de salut". Revue Theologique de Louvain 29 (1998), p. 485.
} 
significado no projeto de Deus para a humanidade, a possibilidade de uma convergência das várias tradições religiosas, com pleno respeito pelas suas diferenças, o seu mútuo enriquecimento e a sua recíproca fecundação" 54 . Este novo enfoque procura compreender e valorizar positivamente a pluralidade religiosa confrontando-a, teologicamente, com o mistério de Deus. Procurase responder, com profundidade, se a pluralidade religiosa é simplesmente um fato da história, ou seja, se é um fenômeno de fato (pluralismo de fato), ou se é um fenômeno fundacional, algo que tem uma razão especifica de ser, algo querido por Deus e que exige uma contínua coexistência humana com o mesmo (pluralismo de princípio) ${ }^{55}$.

Reconhecer o 'pluralismo religioso de princípio' significa desocultar o significado positivo das diversas tradições religiosas na globalidade do único desígnio salvífico de Deus, o que atesta uma mudança significativa do olhar e afirma "a generosidade superabundante com que Deus se manifestou de muitos modos à humanidade e a resposta multiforme que os seres humanos deram à auto-revelação divina nas várias culturas" $"$.

À margem desses intentos de interpretações da existência da pluralidade religiosa, que constituem as diferentes teologias das religiões, tem se desenvolvido um movimento cada vez mais intenso de encontros entre os membros das diferentes religiões.

A existência mesma do diálogo e a forma em que se está desenvolvendo supõem um desafio de uma transcendência insuspeita às tradições. Provavelmente a resposta das diferentes religiões a este desafio depende, em boa medida, do futuro da religião em nosso mundo ${ }^{57}$.

A experiência que supõe para o diálogo inter-religioso a existência de numerosos encontros inter-religiosos destaca a importância que está adquirindo o desenvolvimento do diálogo em que intervém a dimensão espiritual e a experiência interior que comporta todas as religiões. Aqui está a importância que reveste para o melhor desenvolvimento do diálogo entre as religiões a intervenção semelhante desses cultivadores eminentes da experiência religiosa que são os místicos. Isso demonstra a importância decisiva que pode ter a intervenção dos místicos para o diálogo inter-religioso.

\footnotetext{
${ }^{54}$ Id., Rumo a uma teologia cristã, p. 26.

${ }^{55}$ Cf. DUPUIS, Jacques. Rumo a uma teologia cristã, p. 26.

${ }^{56}$ Id., O cristianismo e as religiões, p. 526.

${ }^{57}$ Cf. VELASCO, J. Martin. El fenómeno místico. Estudio comparado. Madri: Trotta, 1999, p. 468.
} 
Todavia, o que se busca em tais diálogos não é tanto a compreensão, mas a comunhão na contemplação: "O nível mais profundo da comunicação não é a comunicação, senão a comunhão. Nesse nível não tem palavras, está além das palavras e também além da linguagem e dos conceitos" ${ }^{58}$.

Essas experiências

mostram a possibilidade de encontros inter-religiosos mais além das ações, dos ritos, as instituições e as crenças, que desembocam no centro de toda experiência religiosa, em seu núcleo místico mais íntimo: o silêncio, a meditação, a oração, a experiência espiritual, o contato interior com a realidade última do que vivem todas as religiões ${ }^{59}$.

As razões que explicam a contribuição verdadeiramente única da mística ao diálogo inter-religioso e, dessa forma, ao desafio que supõe para as religiões consistem na capacidade de realizar a experiência dos serviços que podem prestar e sua radical insuficiência para procurar uma união com Deus, ou com o Último, que se realiza na mais pura e desnuda fé amorosa, na mais absoluta confiança. Porque

o encontro mais profundo terá lugar na esfera da mística, no que vamos mais além das ideias, dos conceitos e das imagens, para um estado de amor silencioso. Aqui as pessoas permanecem em um estado de união sem palavras, aqui o espírito se encontra com o espírito ${ }^{60}$.

Assim, podemos entender que, no diálogo inter-religioso, em que se deve evitar o dogmatismo e o indiferentismo, a mística tem um lugar privilegiado. O místico encontra-se melhor preparado contra todos esses perigos. Contra o dogmatismo, por realizar uma radical relativização de todas as mediações que possui a religião, fazendo, pessoalmente, sua experiência. E, além disso, por ter, na sua religião, a experiência do Mistério como centro, pode valorizar a vida religiosa, seja qual for o lugar em que ela floresça, superando a tentação de absolutista e exclusivista, bem como o perigo do indiferentismo.

\footnotetext{
${ }^{58}$ MERTON, Thomas. Vivir con sabeduria. Madri: PPC, 1997, p. 218.

${ }^{59}$ VELASCO, J. Martin. Op. cit., p. 470.

${ }^{60}$ Ibid., p. 471.
} 


\section{Conclusão}

Estamos certos de que o pluralismo religioso é fruto da própria realidade do mundo. A sociedade é plural, e esta pluralidade encontra-se presente em todos os seus âmbitos, atingindo o cotidiano da vida humana.

Entendemos que no que diz respeito às religiões, a teologia, por causa desta realidade plural, é provocada com a tarefa de interpretar as religiões à luz da revelação cristã, e surpreende-se por esta realidade significar mais que um desafio, por ser uma possibilidade para que o cristianismo reveja toda sua estrutura e renovando-se, adquira uma maior percepção da revelação de Deus, que se dá sem medida.

Constatamos que, diante do pluralismo religioso e da diversidade de posicionamentos, os encontros provocados por esta realidade com o intuito de conhecer as tradições religiosas se tem revelado uma oportunidade de rico crescimento mútuo entre os diversos membros das diversas religiões. E tem-se destacado a importância que está adquirindo para o diálogo inter-religioso a experiência espiritual em todas as religiões. Nesse contexto, podemos destacar os místicos como excelentes cultivadores desta experiência religiosa.

\section{Referências bibliográficas}

AMAladoss, M. Pela estrada da vida. Prática do diálogo inter-religioso. São Paulo: Paulinas, 1996.

BARTH, Karl. La revelación como abolición de la religión. Madri: Morova, 1973.

CONCILIUM. "A teologia católica das religiões numa encruzilhada”. v. 203, n. 1.

Declaração da XII reunião anual da associação de teólogos da Índia, em 28 a 31 de dezembro de 1989. n. 4.

DUPUIS, Jacques. "Le pluralisme religieux dans le plan divin de salut". Revue Theologique de Louvain 29, 1998.

DUPUIS, Jacques. Rumo a uma teologia cristã do pluralismo religioso. São Paulo: Paulinas, 1999.

JAYANTH, Mathew. "De la pluralidad al pluralismo". Selecciones de Teologia 163 (2002), pp. 163-176. 
KNITTER, Paul. Diálogo inter-religioso e ação missionária: preparai os caminhos. São Paulo: CNBB/COMINA, 1994.

MERTON, Thomas. Vivir con sabeduria. Madri: PPC, 1997.

MIRANDA, M. de França. O cristianismo em face das religiões. Religiões em diálogo. São Paulo: Loyola, 1998.

QUEIRUGA, A. Torres. O diálogo das religiões. São Paulo: Paulus, 1997.

SCHILLEBEECK, E. História humana. Revelação de Deus. São Paulo: Paulus, 1994.

SULLIVAN, Francis A. ¿Hay salvación fuera de la Iglesia?. Desclée: Bilbao, 1999.

TEIXEIRA, Faustino. Diálogo de pássaros. Nos caminhos do diálogo inter -religioso. São Paulo: Paulinas, 1993.

TEIXEIRA, Faustino. Teologia das religiões: uma visão panorâmica. São Paulo: Paulinas, 1995.

VELASCO, J. Martin. El fenómeno místico. Estudio comparado. Madri: Trotta, 1999.

VIGIL, J. Maria. Teologia do pluralismo religioso. Para uma releitura pluralista do cristianismo. São Paulo: Paulus, 2006.

Francilaide de Queiroz Ronsi Doutora em Teologia Sistemática pela Pontifícia Universidade Católica do Rio de Janeiro Pós-doutoranda em Ciências da Religião pela Universidade Católica de Pernambuco Bolsista CAPES Recife / PE - Brasil E-mail: francilaide@ig.com.br

Recebido em: 21/05/15

Aprovado em: 08/12/15 